\title{
Stakeholder Management in Complex Project: Review of Contemporary Literature
}

\author{
T. S. Nguyen ${ }^{1}$, S. Mohamed ${ }^{2}$, and K. Panuwatwanich ${ }^{3}$ \\ ${ }^{1} \mathrm{PhD}$ candidate, School of Engineering and Built Environment, Griffith University, Australia. E-mail: \\ tuanson.nguyen@griffithuni.edu.au \\ ${ }^{2}$ Professor, School of Engineering and Built Environment at Griffith University, Australia. E-mail: \\ s.mohamed@griffith.edu.au (corresponding author). \\ ${ }^{3}$ Assistant Professor, School of Civil Engineering and Technology, Sirindhorn International Institute of Technology
}

(SIIT), Thailand. E-mail: kriengsak@siit.tu.ac.th

Project Management
Received January 11, 2018; received revision April 9, 2018; accepted April 20, 2018

Available online June 5, 2018

\begin{abstract}
Previous studies have made vital contributions to the theory and practice of engaging and managing project stakeholders. A literature review plays a critical role in supporting researchers to better understand the research topic, helping researchers identify the boundaries of the current body of knowledge and research trends, and shaping future research. Thus, this paper analyses the latest research developments in stakeholder management within the context of complex projects. It examines articles published between 2005 and 2016, and discusses the relevant trends under four themes: stakeholder analysis, stakeholder influence, stakeholder management strategies and stakeholder engagement. The paper reveals that social network analysis strongly emerges to be a valuable tool for analyzing the complexity of stakeholder interrelationships in the context of CPs. Stakeholder analysis and stakeholder engagement strategies are powerful in addressing environmental complexity (including multiple stakeholders, an environment of changing policy and regulation, and an environment with a changing nature) projects. The paper draws conclusions regarding the findings of the review, and provides some recommendations for future research.
\end{abstract}

Keywords: Stakeholder management, complex projects, research review.

\section{Instruction}

Stakeholder management (SM) plays a critical role in project performance in complex projects (CPs) as a key success factor (Beringer et al., 2012). SM does not just focus on single stakeholders, but accounts for all stakeholders' influence on one another in complex interactions of multiple, and potentially interdependent stakeholders (Beringer et al., 2012). Interestingly, stakeholders' interrelationships themselves are also a source of project complexity (Debrie and Raimbault, 2016; Ommen et al., 2016; Yang, 2014). Complexity is the main source of uncertainty and risk in projects, and it affects project performance if participants fail to address this issue from the beginning (Floricel et al., 2016). These participants can be viewed as stakeholders. The complexity of the projects requires systematic approaches and appropriate project management skills to manage stakeholders to achieve the best value for project performance (Mok et al., 2015).

Previous studies have made a considerable contribution to the theory and practice of engaging and managing stakeholders in projects that are perceived as complex. Williams et al. (2015) examined the network structure of online stakeholders' discussions in the planning stage of a mega project that was highly complex because it was embedded in a network of stakeholders who were either supporting or opposing the project. Aaltonen et al. (2015) sought to advance understandings of stakeholder challenges in CPs by focusing on the planning phase. Their study highlighted how stakeholder dynamics-including stakeholder influence strategies, SM strategies and project contextual conditions-are affected by the interactions between stakeholders' influence, SM activities and the project's contextual conditions.

Although comprehensive literature reviews are vital, there is no previous literature review on SM research in the context of CPs. A literature review plays a critical role in supporting researchers to understand the research topic, helping researchers identify the current body of knowledge and research trends, and shaping future research. Littau et al. (2010) outlined the development of stakeholder theory in project management literature over a 25-year period (1984 to 2009). They found that stakeholder theory is predominantly applied in the construction and information technology sectors, and that understandings of the stakeholder notion have moved 
towards a more complex view. Mok et al. (2015) conducted a literature review on SM studies that focused only on mega construction projects. Eskerod et al. (2015) examined project SM by considering a theory outside the project management field to advance understandings of this topic. However, they emphasised the core argument that the current working forms are not suited to address the increased complexity facing project managers and project teams.

In addition, it is widely recognized in the literature that many projects ultimately fail (Damoah and Akwei, 2017; Sharma et al., 2011). There are many causes of failure, one of which is project complexity, which creates difficulty in completing projects and requires extra effort to overcome (Dao et al., 2016). CPs demand systematic approaches and efficient management skills to manage stakeholders to attain the best outcomes in terms of project performance (Mok et al., 2015). Thus, a comprehensive literature review of SM issues in the context of CPs is necessary to advance understandings of this specific topic. As such, this literature review conducts a critical analysis of SM in the context of CPs in papers published from 2005 to 2016 to answer the research question: what are SM trends in the context of CPs?

This review begins by discussing the fundamentals of SM and CPs, followed by outlining the research methodology that was adopted. The next sections review selected publications under four main themes: stakeholder analysis (SA), stakeholder influence (SI), SM strategies (SMS) and stakeholder engagement (SE). The final section of the paper makes suggestions for future studies.

\section{Background}

The stakeholder concept was first mentioned in 1963 by researchers in an internal memorandum at the Stanford Research Institute. They defined stakeholders as 'those groups without whose support the organization would cease to exist' (cited in Freeman (2010)). From the original work at the Institute, the stakeholder notion has diverged into four main research themes: corporate planning, systems theory, corporate social responsibility and organization theory (Freeman, 2010). To unite these themes, Freeman (1984) introduced a strategic management process - a stakeholder approach that has been widely acknowledged as a milestone in the evolution of SM research, where stakeholders are defined as a party 'who can affect or is affected by the achievement of the firm's objectives'. Following that, many different perspectives of SM have been developed, such as the concepts of stakeholder dynamics (Aaltonen et al., 2015), three aspects of categorizing stakeholder theory (descriptive, instrumental and normative) (Jones, 1995), stakeholder salience and typology (Mitchell et al., 1997), SI strategy (Aaltonen et al., 2008; Frooman, 1999; Hendry, 2005), stakeholder response strategy (Aaltonen and Sivonen, 2009; De Schepper et al., 2014; Savage et al., 1991) and SE (Greenwood, 2007; Strand and Freeman, 2015).

The theory and application of complexity is a significant topic across diverse fields, such as philosophy, mathematics (Bountis et al., 2016), biology, physics, chemistry (Margineanu, 2013; Sherrington, 2010; Whitesides and Ismagilov, 1999), computer science (Eberhard, 2015), technology, engineering (Jamshidi,
2012) and project management (Bosch-Rekveldt et al., 2011; del Puerto et al., 2013; Mozaffari et al., 2012). CPs have received much attention from researchers and project managers because of an increase in the number of CPs worldwide in different fields (Floricel et al., 2016), as well as CP failure because of their complexity (Vidal et al., 2011). In this context, 'complexity' is defined as 'the property of a project which makes it difficult to understand, foresee and keep under control its overall behavior, even when given reasonably complete information about the project system' (Vidal et al., 2011). This definition emphasizes, in theoretical terms, that project complexity is based on both the project's characteristics and the ability of managers to address the diverse factors that affect project outcomes, including disorder, instability, emergence, non-linearity, recursiveness, uncertainty, irregularity and randomness (ICCPM, 2012).

As complexity is an intrinsic property of projects (Floricel et al., 2016), scholars have sought to quantify and measure it (Vidal et al., 2011). He et al. (2015) proposed a complexity measurement model that would benefit researchers and serve as a reference for professionals in managing CPs. The model consists of 28 factors that are grouped into six categories: technological, organizational, goal, environmental, cultural and information complexities. These six categories are used in the current review to classify CPs. The authors selected this model because it is a comprehensive model to classify CPs.

Stakeholder interrelationships are a source of project complexity (Debrie and Raimbault, 2016; Ommen et al., 2016; Yang, 2014). A large number of stakeholders in CPs can lead to: (1) a complex interaction of actors with varying stakes (Afreen and Kumar, 2016; Caniato et al., 2014; Martinez, 2016); (2) conflicting stakeholder interests (Burgin et al., 2013; Yang, 2014), concerns (McKenna and Metcalfe, 2013) and perspectives (Walton, 2013); and (3) inadequate understanding of the complex stakeholders (Sæbø et al., 2011). A complex network of stakeholders may also result in a complex decisionmaking process (Blokhuis et al., 2012) and CP evaluations involving multiple objectives and multiple stakeholder groups (De Brucker et al., 2013; Windapo and Qamata, 2015).

In addition, projects have different phases, such as the conceptual, planning, execution and termination phases. These project phases have dramatically different characteristics (Turner, 2009) and create a dynamic context for managing stakeholders and their behavior as the project shifts through the different phases of its lifecycle (Aaltonen and Kujala, 2010). Thus, a better understanding of SM trends during the CP lifecycle might increase project performance when facing the complexity of projects.

\section{Research Method}

The review process in this paper included two stages: paper collection and content analysis. The paper collection followed the collection protocol (Table 1), which included information about the inclusion/exclusion criteria and search strategy (Jasinski et al., 2015). The content analysis enabled identification of the focused subjects and captured emerging trends in the literature (Elo and Kyngäs, 2008). This section also provides 
overview information regarding the collected articles, such as the number of publications per year, distribution of collected articles by publishers and period, and research themes in relation to the different CP fields.

\subsection{Paper Collection}

Table 1 presents the inclusion/exclusion criteria and literature survey. The inclusion and exclusion criteria were identified based on a review question that represented the scope of the literature review and its characteristics. Only peer-reviewed journal articles were collected for this comprehensive literature review. Papers in conference proceedings, editorials and book reviews were eliminated in consideration of their impact positions in the research community, based on the SCImago Journal Rank and H-index (Mok et al., 2015). The review included only studies reported in English, as the majority of research is published in English, and this minimized the risk of language bias in the results (Jasinski et al., 2015; Pickering and Byrne, 2013). The following databases were considered for searching SM in CPs: ISI Web of Science and Scopus. Both databases cover the major literature sources across the different fields and disciplines areas (Thomas, 2014). The keyword search terms were 'stakeholder' and 'complex project'. The research rules were slightly different because there were slight differences in searching within each database (please see Appendix A for the research rules used for this review). The timeframe for searching was a 20-year period (1 January 1997 to 28 November 2016), but was later revised to 2005-2016, as early published papers did not fully satisfy our search rules. In total, there were 124 collected papers, of which 73 were from Web of Science and 51 were from Scopus. However, some of these papers overlapped. To eliminate duplication of papers, the authors collected all the references (124 articles) and stored them in EndNote. By doing so, the overlapped papers could be easily removed. Moreover, a number of collected papers were deemed irrelevant to the research topic. For instance, some were concerned with managing stakeholders, but not in CPs, and vice versa. The ones that did not contain both keywords of 'stakeholder' and 'complex' were eliminated. This was followed by a brief review of the papers' content. The authors removed papers that were irrelevant to SM in the context of CPs, which left a total of 55 papers for content analysis. The collected publications included the diverse perspectives of managing stakeholders in the context of CPs, including SA, SI, SMS and SE, as well as the theories and practical approaches to addressing SM.

\subsection{Content Analysis}

This review adopted content analysis, which is a structural and systematic process to identify the main research themes for literature reviews. Content analysis is known as a method of analyzing documents, and, through content analysis, 'it is possible to distil words into fewer content-related categories' (Elo and Kyngäs, 2008). Content analysis allows scholars to examine huge quantities of documents in a systematic manner, identify the focused subjects, and capture emerging trends in the literature (Elo and Kyngäs, 2008; Krippendorff and Bauer, 2007; Weber, 1990). This methodology was applied by Laplume et al. (2008) and Mok et al. (2015) in their review of SM theory, in which they identified the main research themes by coding and analyzing using an inductive approach. Table 2 presents the codebook for content analysis in the current review.

\subsection{Overview of Collected Papers}

Through content analysis, this study found that SM research in the context of CPs is categorized under four main themes: SA, SI, SMS and SE. Table 3 and Appendix $\mathrm{B}$ present the distribution of publications by period and identified research themes. The reason we divided the data into two periods (2005 to 2012 and 2013 to 2016) was because, in the four years from 2013 to 2016, the number of articles (35 articles) was nearly double that published in the 2005 to 2012 period (20 articles) (Fig. 1). SA (67.27\%) and SE (56.36\%) appeared more frequently than did SI (5.45\%) and SMS (12.72\%) (Table 3).

There is an increasing trend in the number of publications annually, indicating a growing research interest in this topic in the context of CPs (see Fig. 1). This growth might be attributed to the increase in CPs worldwide and the subsequent increase in issues related to managing stakeholders in CPs (Floricel et al., 2016).

The collected papers were widely distributed across 41 journals. In terms of paper frequency, the top journal was International Journal of Project Management (12.72\%), followed by Project Management Journal (5.54\%) and Environmental Science and Policy (5.54\%) (Table 4).

From our review, it appears that there is a variety of $\mathrm{CP}$ fields (see Table 5). Infrastructure and environment are the fields in which most CPs are being reported, followed by industry and technology, research and development.

Table 1. Collection protocol designed for the literature review process

\begin{tabular}{cc}
\hline Step & Research method \\
\hline Inclusion criteria & Population: Peer-reviewed journal articles representing the SM in CPs \\
Lxclusion criteria & Conguage: English \\
Cearching the literature & Method: Database searching \\
& Databases: ISI Web of Science and Scopus \\
Terms for searching: 'stakeholder' and 'complex project'
\end{tabular}


Table 2. Codebook for content analysis (Adapted from Laplume et al. (2008) and Mok et al. (2015))

\begin{tabular}{cc}
\hline Code & Definition of code \\
\hline Year & Quantitative variables coded \\
Author & Year of publication \\
Article title & List of authors \\
Journal & Title of the article \\
Concern & Publication in which the article was published \\
SM & Primary stakeholders, secondary stakeholders, or both \\
Project & Theoretical terms in regard to stakeholders \\
Methodology & Type of CP, project phases \\
Data source & Qualitative, quantitative, mixed methods \\
Industry & Survey, interview, secondary data, others \\
& Industry from which the data were collected \\
\hline Research questions & Qualitative variables coded \\
Contributions & Research question explicitly stated in the article \\
Main findings & Contributions explicitly stated in the article \\
\end{tabular}

Table 3. Distribution of publications by period and identified research themes

\begin{tabular}{cccccc}
\hline \multirow{2}{*}{ Research theme } & \multicolumn{2}{c}{ Period } & \multirow{2}{*}{ Total } & Percentage (\%) ${ }^{1}$ \\
\cline { 2 - 4 } & $2005-2012$ & $2013-2016$ & 37 & 67.27 \\
SA & 15 & 22 & 3 & 5.45 \\
SI & 2 & 1 & 7 & 12.72 \\
SE & 4 & 18 & 31 & 56.36 \\
\hline
\end{tabular}

${ }^{1}$ The total percentage is higher than $100 \%$ because a number of papers had more than one theme.

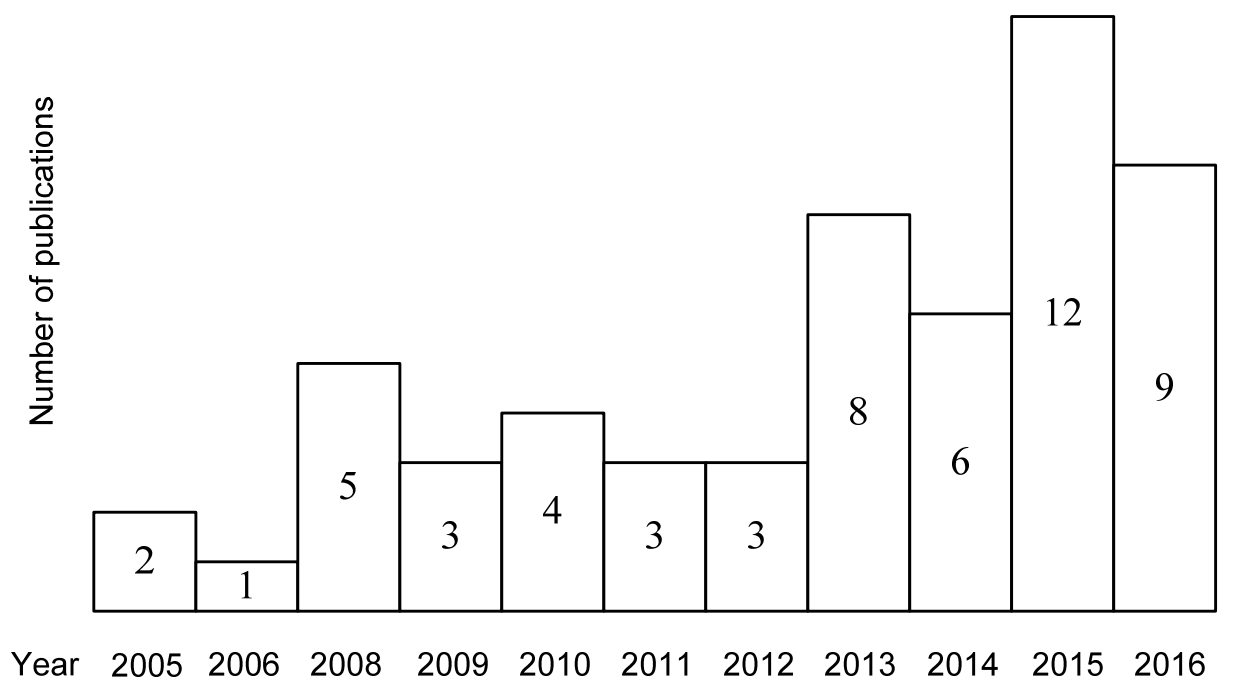

Fig.1. Number of publication papers 
Table 4. Journals containing most SM in CPs papers

\begin{tabular}{cccc}
\hline No. & Journal containing two or more papers & Number of papers & Percentage of papers (\%) \\
\hline 1 & International Journal of Project Management & 7 & 12.72 \\
2 & Project Management Journal & 3 & 5.45 \\
3 & Environmental Science and Policy & 3 & 5.45 \\
4 & Climatic Change & 2 & 3.63 \\
5 & Construction Management \& Economics & 2 & 3.63 \\
6 & International Journal of Managing Projects in Business & 2 & 3.63 \\
7 & Land Use Policy & 2 & 3.63 \\
8 & Ocean \& Coastal Management & 2 & 3.63 \\
\hline
\end{tabular}

${ }^{2}$ The total percentage does not equal $100 \%$ as only the journals with the most papers are shown.

Table 5. CP fields

\begin{tabular}{ccc}
\hline CP types & Number of paper & Percentages (\%) $)^{3}$ \\
\hline Infrastructure & 23 & 41.81 \\
Environment & 14 & 25.45 \\
Technology, research and development & 5 & 9.09 \\
Industry & 6 & 10.90 \\
Health & 3 & 5.45 \\
Information communication technology & 4 & 7.27 \\
Rural and agriculture & 3 & 5.45 \\
Turnkey & 1 & 1.81 \\
Mega engineering & 1 & 1.81 \\
\hline
\end{tabular}

${ }^{3}$ The total percentage is higher than $100 \%$ because a number of projects had more than one type.

\section{Literature Review}

This section discusses the four main themes revealed through the content analysis. Table 3 presents the distribution of publications by period and the identified research themes. It indicates that researchers have devoted much attention to SA and SE, yet less attention to SMS and SI. Each of the following subsections review the current development of each theme in the context of $\mathrm{CPs}$ and then present a brief conclusion.

\subsection{Stakeholder Analysis}

SA can be defined as a technique of systematically gathering and analyzing both quantitative and qualitative information to determine who should be considered during the project lifecycle (PMI, 2008). SA addresses stakeholder identification, classification and assessment (Mok et al., 2015; PMI, 2008).

It is interesting to note that the literature indicates that a stakeholder matrix to classify and characterize stakeholders is still relevant in current research on SA as applied to CPs (Aaltonen et al., 2008; Aaltonen and Kujala, 2010; Aaltonen et al., 2015; Sæbø et al., 2011). Pacagnella Júnior et al. (2015) applied the power/interest matrix to describe and classify main stakeholders according to their levels of power and interest in the implementation of CPs. Other stakeholder matrices used different stakeholder characteristics have also been developed, such as: influence and interest in the SI and stakeholder interest matrix in the complex contexts where multiple organizational interact (Ballejos and Montagna, 2008). This matrix was proposed to deal with difficulty and complexity in a project with several involved organizations. In addition, combining power position and urgency position, De Schepper et al. (2014) introduced the SI identification matrix. This matrix has enormously contributed to overcome the difficulty of the increasing importance of the stakeholder context and dynamic in Public-Private Partnerships (PPPs) project, in which makes stakeholder environment more complex to manage. However, the limitation of the above stakeholder matrix approaches is their failure to capture whether stakeholder attitudes, towards the project, are positive or negative.

To overcome some limitations of stakeholder salience, stakeholder position and the stakeholder matrix, Aaltonen et al. (2015) developed a salience/position matrix to analyze changes in stakeholders' importance and position in complex nuclear projects. This model can classify stakeholders depending on their degree of salience (low to high degree of salience) and degree of supportiveness (unsupportive or supportive). By applying the salience/position model, a manager can capture both stakeholders' power and attitudes. They may subsequently attain a better picture of the stakeholders and can develop an effective SM strategy for each stakeholder group. However, each of the above models represent an empirical perspective that cannot overcome the cognitive limitations of core stakeholders (Yang, 
2014), and the accuracy of the models' results may decrease when the complexity of the project increases (Pryke et al., 2006).

Yang (2014) reported methods for identifying and prioritizing stakeholders and their interests, and two perspectives (empiricism and rationalism) for SA in order to deal with relatively complex stakeholder interests and relationships in projects. Yang (2014) reported using Stakeholder Circle $^{\mathrm{TM}}$ and social network analysis (SNA) to represent the empiricism and rationalism perspectives for SA, respectively. Stakeholder Circle was developed to map and visualize stakeholder power and influence (Bourne and Walker, 2005). It was developed for project managers to identify and prioritize key project stakeholders, and then develop an effective engagement strategy and communications plan to maintain robust relationships with these key stakeholders. SNA was developed based on the assumptions that network members are interdependent and their behavior is confined by relationship patterns within the network structure (Wasserman et al., 1994). There are two advantages to using the SNA when analyzing stakeholders. First, the quantitative evaluation of networks provides more analysis of stakeholders' influence. Second, SNA allows the visualization of complex and brief stakeholder relationships at different project phases (Chinowsky et al., 2008). SNA involves analyzing stakeholders' structural relationships, rather than only examining the characteristics of individual stakeholders (Nogueira and Pinho, 2015; Rowley, 1997).

There has been an increase in the application of SNA to analyze stakeholders in CPs (Caniato et al., 2014; Nogueira and Pinho, 2015; Williams et al., 2015; Yang and Zou, 2014) to reveal the interrelationships between stakeholders. Caniato et al. (2014) integrated SA regarding power, interest and attitude with SNA to analyze both stakeholder characteristics and interactions, in which SNA analyzed the stakeholder interactions. Nogueira and Pinho (2015) used the SNA methodology to understand the nature of interactions among different stakeholders. Using SNA involves not only an inspection of main stakeholders, but also the identification of structural multiple stakeholders by applying SNA to analyze stakeholders (Cooper et al., 2009; Nogueira and Pinho, 2015). Williams et al. (2015) applied SNA to examine the network structure of online stakeholder discussions in highly CPs to reveal the stakeholder groups who might support or oppose the project.

In conclusion, many tools and approaches have been developed to analyze stakeholders in the context of CPs. For instance, the SI and stakeholder interest matrix is to deal with the CPs where a multiple organizational involvement is. The SI identification matrix is to tackle dynamic stakeholder context in complex PPPs project. The salience/position matrix is to overcome the changing in stakeholders' importance and position in complex nuclear projects. Particularly, SNA strongly appears to be a tool for analyzing the complexity of stakeholder interrelationships in the context of CPs.

\subsection{Stakeholder Influence Strategies}

SI can be considered as strategies for stakeholders might be applied to increase the likelihood that their requirements will be considered in the project management's decision-making process (Aaltonen et al.,
2008; Aaltonen et al., 2015; Frooman, 1999; Hendry, 2005).

In the context of CPs, Aaltonen et al. (2008) identified diverse strategies that stakeholders might use to increase their salience in the complex global project, including: (1) direct withholding, (2) indirect withholding, (3) coalition building, (4) resource building, (5) conflict escalation, (6) creditability building, (7) communication and (8) direct action strategy (Appendix C). These strategies might help stakeholders increase their salience and influence in a CP by affecting the project's access to resources in various ways, or even using media and organizing protests.

As mentioned early in the previous subsection, by combining power and urgency in a matrix, De Schepper et al. (2014) identified three different types of potential SI in CPs. Type A has a minor influence on the project and the uncertainty in the environment. Type B might have a potential influence on the project and the uncertainty in the environment. Type $\mathrm{C}$ has a direct influence on the project and its environment. As De Schepper et al. (2014) identified three type of SI levels, the authors proposed three SMSs - namely, inform, involve, and collaborate (please refer to the next subsection for more detail) to mitigate the stakeholder issues in a complex PPPs project.

In conclusion, research on SI strategies has received less attention from scholars, as can be seen in Table 3 . However, a number of SI strategies have been reported in the context of CPs, such as direct withholding, indirect withholding, coalition building, resource building, conflict escalation, creditability building, communication and direct action strategy. Different SI levels in a CP have also been identified. These influence strategies are used by stakeholders to increase the chance that their claims will be taken into account in the decision-making project of CPs.

\subsection{Stakeholder Management Strategies}

SMS are undertaken by the project management team and can be seen as activities that may change the level of stakeholders' salience or stakeholders' position towards the projects (Aaltonen et al., 2015). Managers should differentiate their SMS based on the positions of stakeholders (Olander and Landin, 2005).

To manage PPPs projects that make SM more complex, De Schepper et al. (2014) developed four different approaches of relating to stakeholders: inform, involve, collaborate and even ignore- - depending on the group of stakeholders that are identified based on power and urgency position. Open houses, information kiosks, newsletters and websites are potential ways of informing stakeholders (De Schepper et al., 2014; El-Gohary et al., 2006). Regarding involving stakeholders, it is recommended that the focal organizations organize activities such as opinion polls, surveys and meetings with community leaders and landowners, as well as involving stakeholders in working groups (De Schepper et al., 2014; El-Gohary et al., 2006; Morsing and Schultz, 2006). At the collaboration level, De Schepper et al. (2014) suggested that it is necessary to collaborate with definitive stakeholders.

Pacagnella Júnior et al. (2015) proposed four strategies to manage the stakeholders in complex science park projects: collaborate, involve, monitor and defend. Regarding the collaboration strategy, they suggested that 
managers support stakeholders to prevent potential dangers and gain support for the project. Regarding the involvement strategy, they argued that managers should demonstrate the advantages of the project to stakeholders, and then encourage stakeholders for active engagement. In the monitor strategy, they recommended that managers need to observe stakeholders during the project, and continuously verify their changes. Finally, in the defence strategy, managers should be prepared to reduce or eliminate any negative effects that might originate from stakeholders. These strategies for managing stakeholders are also known as 'stakeholder response strategies'.

Stakeholder response strategies can be understood as the strategies project managers may apply in response to stakeholder pressure (Aaltonen and Sivonen, 2009). Aaltonen and Sivonen (2009) identified five response strategies to stakeholder pressure in a global project: (1) adaptation, (2) compromising, (3) avoidance, (4) dismissal and (5) influence strategy. They suggested that selection of these strategies depends on the position, power and legitimacy of stakeholders. In their empirical case study analysis of a CP, they presented an example of how proactive influence strategies enacted by project management-including an active dialogue and early engagement-changed unsupportive stakeholders into neutral ones (Aaltonen and Sivonen, 2009).

In conclusion, SMS encompass various techniques, including informing, involving stakeholders by sharing information and maintaining satisfaction, adapting, collaborating and proactive influencing. Stakeholders can also be controlled by compromising, avoiding and defending. These strategies can be suitably used for different stakeholder types in CPs (e.g. PPPs, complex science project, and global project) to reduce stakeholder issues in CPs or even change their attitudes towards the project (change unsupportive stakeholders into neutral ones).

\subsection{Stakeholder Engagement}

SE includes communicating, involving and improving relationships with stakeholders (Chinyio and Akintoye, 2008; Greenwood, 2007), to ensure that stakeholders participation in the decision-making process throughout the project lifecycle (Cascetta et al., 2015). The two main levels of SE are involvement and participation. Involvement encompasses both informing and consulting as a means to increase stakeholders' knowledge about the project, while participation encompasses a higher level of engagement to reduce potential stakeholder conflicts (Deegan and Parkin, 2011). SE indicates that stakeholders have been given the opportunity to voice their views, influence the project plans, and know what has been decided (Turner and Zolin, 2012). The overall goal of engagement is to achieve a transparent decision-making process, with greater input from stakeholders and with stakeholder support for the decisions that are made (Cascetta et al., 2015).

Previous research has identified SE as a key factor in project success (Turner and Zolin, 2012) and the successful management of a CP network (Hwang and Ng, 2016). The early contributions of both internal and external stakeholders are of great significance (Zidane et al., 2015). Ensuring the early involvement of interested parties can avoid or diminish the negative effects caused by these stakeholders. Openness, dialogue and active engagement of stakeholders-especially during the planning phases of a project-can reduce the potential for conflict in the later project phases (Aaltonen, 2011).

Researchers have developed many approaches for engaging stakeholder in CPs. Henriksen and Barlebo (2008) proposed an approach that includes seven steps of stakeholder involvement: (1) define the context; (2) identify the factors, actions and indicators; (3) build pilot networks; (4) collect data; (5) define states; (6) construct conditional probability tables and (7) collect feedback from stakeholders. Chung et al. (2009) developed an innovative collaborative approach to encourage stakeholder involvement by improving the efficiency and effectiveness of managing large groups of stakeholders through applying communication technology in a briefing for megaprojects. The five core elements in the framework are: (1) an integrated briefing team, (2) a collaborative briefing job plan, (3) a computer-supported cooperative work platform, (4) requirements processing models and (5) facilitation models (Chung et al., 2009). Luyet et al. (2012) proposed a comprehensive framework for implementing stakeholder participation in an environmentally $\mathrm{CP}$, which includes six steps: (1) stakeholder identification, (2) stakeholder characterization, (3) determining the degree of involvement, (4) selecting participatory techniques, (5) implementing participatory techniques and (6) evaluation. O'Toole et al. (2013) developed the concept of participatory logic based on participatory SE for coastal management projects that represented complex ecological systems. It included five main concepts: (1) institutionalizing the processes that drive stakeholder coproduction and co-management; (2) upholding the ability and capacity to make valuable decisions in the process when changing the conditions; (3) including all stakeholders in the process; (4) ensuring the flexibility and willingness of central policies to allow participation by stakeholders at a local level; and (5) allowing pathways for the uptake of all knowledge systems, including building the capacity of stakeholders to fully comprehend other knowledge forms.

Many SE practice strategies have been applied in CPs. Henriksen and Barlebo (2008) suggested that stakeholder involvement plans and guidelines are strongly recommended. In more detail, Luyet et al. (2012) identified the participatory techniques that have already been reported in the literature, such as newsletters, reports, presentations, public hearings, internet web pages, interviews, questionnaires, surveys, field visits, interactions, workshops, participatory mapping, focus groups, citizen juries, geospatial/decision support systems, cognitive maps, role playing, multi-criteria analysis, scenario analysis and consensus conferences. Different SE methods have also been established and promoted via social media to collect additional stakeholder information, such as newsletters, project websites, hotlines and community forums (Yang, 2014). Sensitizing stakeholders through meetings and informal discussions is also a good strategy aimed at presenting the potential benefits of the project (Pacagnella Júnior et al., 2015).

One of the essential characteristics of SE is the degree of engagement in CPs. Yang et al. (2011) emphasized that SM is not only about analyzing who is involved and how, but also about determining their level of engagement in the project. The three levels of involvement range from 
moderate (e.g., treating stakeholders with respect), to intermediate (e.g., incorporating some stakeholder interests in the governance of the corporations), to demanding (e.g., the participation of all stakeholders in the decision processes) (Hendry, 2001). Information, consultation, collaboration, co-decision and empowerment are the five levels of involvement used by Luyet et al. (2012)'s model. The information level involves explanation of the project to the stakeholders. The consultation level involves presenting the project to stakeholders, collecting stakeholders' suggestions, and then making decisions with or without considering the stakeholders' input. The collaboration level involves presenting the project to stakeholders, collecting stakeholders' suggestions, and then making decisions by considering the stakeholders' input. The co-decision level involves cooperating with stakeholders towards an agreement for solution and implementation. The empowerment level involves delegating decision making for the project development and implementation to the stakeholders. Cascetta et al. (2015) also proposed five levels of SE: identification, listening, presenting information to the public, consultation and participation.

In conclusion, SE plays a critical role in managing stakeholders in the context of CPs. Many approaches have been developed to engage stakeholders, such as listening, informing, consulting, involving, participating, collaborating, co-decision making and empowering. From these approaches, many participatory techniques have been applied. In addition, the degree of engagement in CPs plays a major role in determining the participation techniques for the specific group of stakeholders.

\section{Discussion and Future Research}

Fig. 2 displays the four themes as they relate to project phases and project complexity characteristics. It shows what was reported in the selected articles regarding SM in the context of CPs. The topics on the left and right side are the reported SMS in each research theme for CPs. The topics in the middle are the project phases and five categories of CPs. As seen from Fig. 2, regarding the CP categories, SE is linked to technical, organizational, goal, environmental and cultural complexity. This means that SE has been studied in the context of CPs in relation to all project complexity characteristics, with the exception of information complexity. This figure also indicates that there have been no studies on SA, SI, and SMS in the context of CPs in relation to information complexity. Similar trends can be seen in the Figure as not all the four themes are linked with each and every one of the six complexity characteristics.

The discussion of the four themes, presented thus far, sheds the light on the links between one theme and another. For example, by carrying out a critical SA, a project manager will better understand what influential strategies stakeholders might use, as well as what SMS might be suitable for different groups of stakeholders. For instance, stakeholder type A with a minor influence, stakeholder type $\mathrm{B}$ with a potential influence and stakeholder type $\mathrm{C}$ with a direct influence can be identified in the SA, while their respective SMS are informing, involving and collaborating. Similarly, the project manager can determine the best SE level, and apply the most efficient engagement practice strategy. SE mostly focuses on involving and participating with stakeholders, such as giving information to the public, gaining feedback, collaborating, co-decision making and even empowerment. Further, with SMS, one can see a broad range of strategies, ranging from informing and involving stakeholders to keep them informed and satisfied; to adapting, involving and proactively influencing stakeholders; to avoiding and dismissing stakeholders.

The research trend of SM in the context of CPs is to employ SA and SE in the project planning phases, and focus on having multiple stakeholders and changes in policy, regulation and nature. In the context of CPs, most SM research appears to focus on the planning phase of CPs, with a total of 18 reported articles, followed by the execution and conceptualization phases, with a total of 14 and 10 articles, respectively (Appendix D). Studies on $\mathrm{SM}$ in the termination phase of CPs have received less attention from scholars, with only six articles reported. This is understandable because, at the termination phase, most of the issues regarding SM should have already been addressed in previous project phases. In more detail, there is a stronger focus on SA (13 articles) and SE (11 articles) in the planning phase of CPs, and less attention on SI (one article) and SMS (two articles) in the termination phase (Table 6).

Table 7 shows the number of reported articles, in which projects are categorized into the different types of complex characteristics (He et al., 2015), against SA, SI, SMS and SE. Projects are labelled as complex based on diverse characteristics that are not solely technical. Only four of the 55 journal articles referred to projects as complex because of their technical characteristics. The technological complexity factor includes the following sub-factor: diversity of technology in the project, the dependence of technological processes, the interaction between the technology system and the external environment and risk of using highly difficult technology (He et al., 2015). Interestingly, the highest number is recorded by research studies addressing SA and SE in environmental CPs, totaling 31 and 27 articles, respectively. The three main characteristics of environmental CPs are multiple stakeholders (Aaltonen, 2011; Afreen and Kumar, 2016; Burgin et al., 2013), an environment of changing policy and regulation (Aaltonen and Kujala, 2010; Elias, 2012) and an environment with a changing nature (Herazo and Lizarralde, 2016; Rizzo et al., 2015). It means that the SA strategies and the SE strategies are effective in the context of CPs where the complexity of the project comes from multiple stakeholders, an environment of changing policy and regulation, and an environment with a changing nature.

The current development status of SA in CPs is still based on traditional methods, such as stakeholder attributes, stakeholder salience and stakeholder matrices. These techniques play a major role in traditional projects; however, they emphasize individual stakeholder position, power, attributes and salience. Therefore, in the context of CPs, accuracy in the expected outcomes might not be achieved when the complexity of the projects increases. SNA appears to be a suitable tool to analyze stakeholder interactions in the context of CPs; however, it might not be a valuable tool for analyzing individual stakeholder attributes, such as power, interest, attitude and position. Thus, combining traditional SA and SNA should be considered to obtain a more complete picture of stakeholders in the context of CPs. In addition, future 
empirical research should test the applicability and effectiveness of the above mentioned frameworks, tools and techniques for analyzing and classifying stakeholders in different CPs.

Research investigations into SI in the context of CPs are lacking. This statement is reinforced by the data shown in Table 3 . To better manage stakeholders, project managers should be able to understand how stakeholders can influence project outcomes. Therefore, it is vital to determine how a stakeholder might influence CPs, and which SI strategies are most effective. In doing so, complex stakeholder interrelationships in CPs may be addressed more efficiently. Both SI and SMS play a critical role in changing stakeholders' salience, attributes and positions towards a project. However, the connections between SI and management strategies in CPs have rarely been studied in previous research. Moreover, a systematic empirical study of the role of these activities and how they can be practiced in real-life CPs has been limited. Therefore, it is critical to investigate the connection between SI and SMS, as well as how these strategies are practiced and evaluated in the context of CPs.
SE is becoming an emerging trend for managing stakeholders to gain the advantages discussed in the above section. Therefore, it is vitally important for understanding SE and actively engaging stakeholders in the management of CPs. An investigation into the most common and effective approaches for engaging stakeholders and SE strategies in CPs should be considered. SA, SI and SE all include investigation into different levels of stakeholders (operational, tactical and strategic levels), determining the level of SI (minor, potential and direct influence) and determining the degree of involvement (informing, consulting, collaborating, codecision making and empowering) and level of engagement (identifying, listening, informing the public, consulting and participating). Therefore, an investigation into SM in the context of CPs should include identifying the levels of engagement and SI. As expected, different levels of SE require different practical techniques. Thus, it is necessary to investigate the interrelationship between the level of SE and the relevant engagement approaches and strategies.

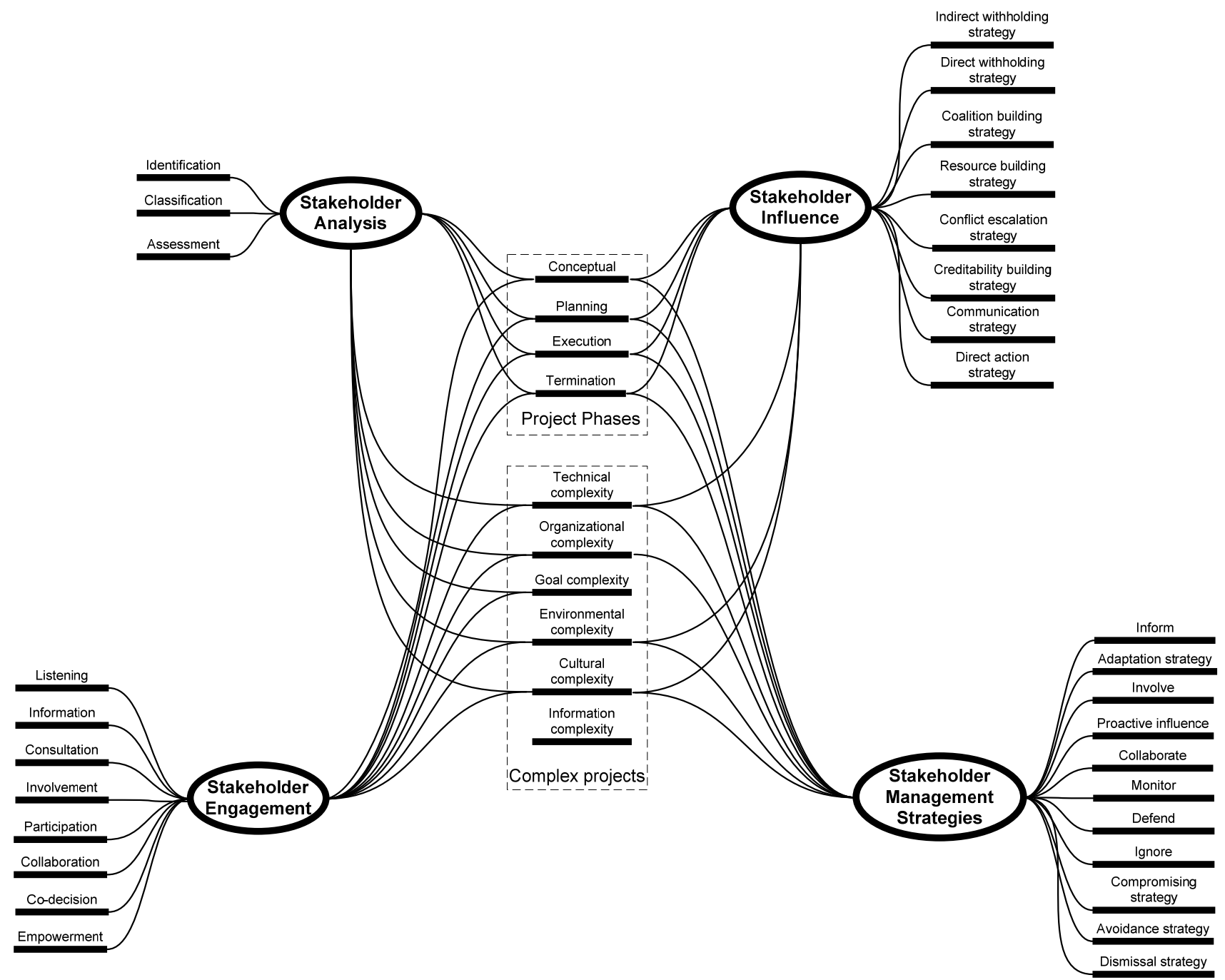

Fig. 2. Relationship between SM, project phases and project complexity 
Table 6. SM and project phases

\begin{tabular}{ccccc}
\hline & SA & SI & SMS & SE \\
\hline Conceptual & 10 & 2 & 3 & 5 \\
Planning & 13 & 2 & 6 & 11 \\
Execution & 10 & 2 & 4 & 7 \\
Termination & 6 & 1 & 2 & 3 \\
\hline
\end{tabular}

Table 7. SM and CPs

\begin{tabular}{lcccc}
\hline & SA & SI & SMS & SE \\
\hline Technical complexity & 2 & 1 & 1 & 2 \\
Organisational complexity & 4 & 0 & 1 & 1 \\
Goal complexity & 2 & 0 & 0 & 4 \\
Environmental complexity & 31 & 2 & 4 & 27 \\
Cultural complexity & 3 & 2 & 2 & 1 \\
Information complexity & 0 & 0 & 0 & 0 \\
\hline
\end{tabular}

\section{Conclusion}

SM in CPs has received attention from both industry and academia because of the increase in number of CPs worldwide. As a result of the significant issues experienced by contemporary practitioners in managing stakeholders in CPs, researchers have invested effort into improving stakeholder theory and management practice in this area. However, previous reviews have been broad and the study focus was not specific to CPs. Moreover, the current working forms are not suited to addressing the increased complexity facing project managers and project teams.

This paper has presented a comprehensive literature review of SM in the context of CPs, focusing on articles published between 2005 and 2016. The review aimed to advance understandings of this topic, as well as highlighting the current study status and trends. This critical review should be of value for advancing understandings of this topic. The review discovered SNA strongly emerge to be a valuable tool for analyzing the complexity of stakeholder interrelationships in the context of CPs. In addition, SA strategies and SE strategies are powerful in addressing environmental complexity projects.

The review identified tools and approaches that have been applied to analyze stakeholders in the context of CPs, each of which has advantages and limitations. Combining traditional SA and SNA should be considered to obtain a more complete picture of stakeholders in the context of CPs. In addition, future empirical research should test the applicability and effectiveness of the above frameworks, tools and techniques for analyzing and classifying stakeholders in different CPs.

Despite the need to understand how stakeholders can influence CPs and determine the more popular SI strategies, studies on SI in the context of CPs are lacking. Therefore, these gaps need to be filled. As such, it would be valuable to investigate the connections between SI and
SMS, as well as how these strategies are practiced in the context of CPs.

Some research trends for managing stakeholders in CPs should be examined. First, SE is a trend in managing stakeholders in a CP; thus, an investigation into the most popular approach for engaging stakeholders and SE practice strategies should be considered. In addition, the interrelationships between the level of SE and the SE approach and practice strategies are vitally important. Second, another research trend of SM in the context of CPs is using SA and SE in the planning phases, and focusing on multiple stakeholders and changes in policy, regulation, technology, economy and nature. Thus, this research trend needs to be continuous. Moreover, it is critical to investigate which SMS are effective in the different phases of CPs.

The basic study limitations of this review are that it is based on publications from a certain period and the collected papers are based on specific keywords; thus, the findings may not have covered all the studies published on this particular topic.

\section{Acknowledgements}

The work described in this paper was fully supported by Griffith University, Australia.

\section{References}

Aaltonen, K. (2011). Project stakeholder analysis as an environmental interpretation process. International Journal of Project Management, 29(2), 165-183.

Aaltonen, K., Jaakko, K., and Tuomas, O. (2008). Stakeholder salience in global projects. International Journal of Project Management, 26(5), 509-516.

Aaltonen, K. and Kujala, J. (2010). A project lifecycle perspective on stakeholder influence strategies in global projects. Scandinavian Journal of Management, 26(4), 381-397.

Aaltonen, K., Kujala, J., Havela, L., and Savage, G. (2015). Stakeholder Dynamics During the Project 
Front-End: The Case of Nuclear Waste Repository Projects. Project Management Journal, 46(6), 15-41.

Aaltonen, K. and Sivonen, R. (2009). Response strategies to stakeholder pressures in global projects. International Journal of Project Management, 27(2), 131-141.

Afreen, S. and Kumar, S. (2016). Between a rock and a hard place The dynamics of stakeholder interactions influencing corporate sustainability practices. Sustainability Accounting Management and Policy Journal, 7(3), 350-375.

Ariza, E., Lindeman, K. C., Mozumder, P., and Suman, D. O. (2014). Beach management in Florida: Assessing stakeholder perceptions on governance. Ocean \& Coastal Management, 96, 82-93.

Bal, M., Bryde, D., Fearon, D., and Ochieng, E. (2013). Stakeholder Engagement: Achieving Sustainability in the Construction Sector. Sustainability, 5(2), 695-710.

Ballejos, L. C. and Montagna, J. M. (2008). Method for stakeholder identification in interorganizational environments. Requirements Engineering, 13(4), 281297.

Beringer, C., Jonas, D., and Gemunden, H. G. (2012). Establishing Project Portfolio Management: An Exploratory Analysis of the Influence of Internal Stakeholders' Interactions. Project Management Journal, 43(6), 16-32.

Blokhuis, E. G. J., Snijders, C. C. P., Han, Q., and Schaefer, W. F. (2012). Conflicts and cooperation in brownfield redevelopment projects: Application of conjoint analysis and game theory to model strategic decision making. Journal of Urban Planning and Development, 138(3), 195-205.

Bosch-Rekveldt, M., Jongkind, Y., Mooi, H., Bakker, H., and Verbraeck, A. (2011). Grasping project complexity in large engineering projects: The TOE (Technical, Organizational and Environmental) framework. International Journal of Project Management, 29(6), 728-739.

Bountis, T., Johnson, J., Provata, A., and Tsironis, G. (2016). The science of complexity and the role of mathematics. The European Physical Journal Special Topics, 225(6), 883-890.

Bourne, L. and Walker, D. H. T. (2005). Visualising and mapping stakeholder influence. Management Decision, 43(5), 649-660.

Bowden, A. R., Pershke, D. F., and Chalaturnyk, R. (2013). Biosphere risk assessment for CO2 storage projects. International Journal of Greenhouse Gas Control, 16, Supplement 1, S291-S308.

Burgin, S., Webb, T., and Rae, D. (2013). Stakeholder engagement in water policy: Lessons from peri-urban irrigation. Land Use Policy, 31, 650-659.

Caniato, M., Vaccari, M., Visvanathan, C., and Zurbrugg, C. (2014). Using social network and stakeholder analysis to help evaluate infectious waste management: A step towards a holistic assessment. Waste Management, 34(5), 938-951.

Cascetta, E., Carteni, A., Pagliara, F., and Montanino, M. (2015). A new look at planning and designing transportation systems: A decision-making model based on cognitive rationality, stakeholder engagement and quantitative methods. Transport Policy, 38, 27-39.

Chinowsky, P., Diekmann, J., and Galotti, V. (2008). Social Network Model of Construction. Journal of
Construction Engineering and Management, 134(10), 804-812.

Chinyio, E. A. and Akintoye, A. (2008). Practical approaches for engaging stakeholders: findings from the UK. Construction Management and Economics, 26(6), 591-599.

Chung, J. K. H., Kumaraswamy, M. M., and Palaneeswaran, E. (2009). Improving megaproject briefing through enhanced collaboration with ICT. Automation in Construction, 18(7), 966-974.

Cooper, C., Scott, N., and Baggio, R. (2009). Network Position and Perceptions of Destination Stakeholder Importance. Anatolia, 20(1), 33-45.

Damoah, I. S. and Akwei, C. (2017). Government project failure in Ghana: a multidimensional approach. International Journal of Managing Projects in Business, 10(1), 32-59.

Dao, B., Kermanshachi, S., Shane, J., Anderson, S., and Hare, E. (2016). Identifying and Measuring Project Complexity. Procedia Engineering, 145, 476-482.

Davis, J., MacDonald, A., and White, L. (2010). Problemstructuring methods and project management: an example of stakeholder involvement using Hierarchical Process Modelling methodology. The Journal of the Operational Research Society, 61(6), 893-904.

De Brucker, K., Macharis, C., and Verbeke, A. (2013). Multi-criteria analysis and the resolution of sustainable development dilemmas: A stakeholder management approach. European Journal of Operational Research, 224(1), 122-131.

De Schepper, S., Dooms, M., and Haezendonck, E. (2014). Stakeholder dynamics and responsibilities in Public-Private Partnerships: A mixed experience. International Journal of Project Management, 32(7), 1210-1222.

Debrie, J. and Raimbault, N. (2016). The port-city relationships in two European inland ports: A geographical perspective on urban governance. Cities, 50, 180-187.

Deegan, B. and Parkin, J. (2011). Planning cycling networks: human factors and design processes. Proceedings of the ICE-Engineering Sustainability, 164(1), 85-93.

del Puerto, C. L., Gransberg, D. D., Strong, K., and Shane, J. S. (2013). Project Complexity Mapping in Five Dimensions for Complex Transportation Projects. Journal of Management in Engineering, 29(4), 316326.

Eberhard, S. (2015). Applicative theories for logarithmic complexity classes. THEORETICAL COMPUTER SCIENCE, 585, 115-135.

El-Gohary, N. M., Osman, H., and El-Diraby, T. E. (2006). Stakeholder management for public private partnerships. International Journal of Project Management, 24(7), 595-604.

Elias, A. A. (2012). A system dynamics model for stakeholder analysis in environmental conflicts. Journal of Environmental Planning and Management, 55(3), 387-406.

Elo, S. and Kyngäs, H. (2008). The qualitative content analysis process. Journal of advanced nursing, 62(1), 107-115.

Eskerod, P., Huemann, M., and Savage, G. (2015). Project Stakeholder Management-Past and Present. Project Management Journal, 46(6), 6-14. 
Floricel, S., Michela, J. L., and Piperca, S. (2016). Complexity, uncertainty-reduction strategies, and project performance. International Journal of Project Management.

Freeman, R. E. (1984). Strategic management: a stakeholder approach. Boston: Pitman.

Freeman, R. E. (2010). Strategic management: A stakeholder approach: Cambridge University Press.

Frooman, J. (1999). Stakeholder Influence Strategies. The Academy of Management Review, 24(2), 191-205.

Fulton, E. A., Boschetti, F., Sporcic, M., Jones, T., Little, L. R., Dambacher, J. M., . . . and Gorton, R. (2015). A multi-model approach to engaging stakeholder and modellers in complex environmental problems. Environmental Science \& Policy, 48, 44-56.

Gramberger, M., Zellmer, K., Kok, K., and Metzger, M. J. (2015). Stakeholder integrated research (STIR): a new approach tested in climate change adaptation research. Climatic Change, 128(3-4), 201-214.

Greenwood, M. (2007). Stakeholder Engagement: Beyond the Myth of Corporate Responsibility. Journal of Business Ethics, 74(4), 315-327.

Havard, L., Brigand, L., and Carino, M. (2015). Stakeholder participation in decision-making processes for marine and coastal protected areas: Case studies of the south-western Gulf of California, Mexico. Ocean \& Coastal Management, 116, 116-131.

He, Q. H., Luo, L., Hu, Y., and Chan, A. P. C. (2015). Measuring the complexity of mega construction projects in China-A fuzzy analytic network process analysis. International Journal of Project Management, 33(3), 549-563.

Hendry, J. (2001). Missing the Target: Normative Stakeholder Theory and the Corporate Governance Debate. Business Ethics Quarterly, 11(1), 159-176.

Hendry, J. R. (2005). Stakeholder Influence Strategies: An Empirical Exploration. Journal of Business Ethics, 61(1), 79-99.

Henriksen, H. J. and Barlebo, H. C. (2008). Reflections on the use of Bayesian belief networks for adaptive management. Journal of Environmental Management, 88(4), 1025-1036.

Herazo, B. and Lizarralde, G. (2016). Understanding stakeholders' approaches to sustainability in building projects. Sustainable Cities and Society.

Hjortso, C. N., Christensen, S. M., and Tarp, P. (2005). Rapid stakeholder and conflict assessment for natural resource management using cognitive mapping: The case of Damdoi Forest Enterprise, Vietnam. Agriculture and Human Values, 22(2), 149-167.

Hwang, B. G. and Ng, H. B. (2016). Project network management: risks and contributors from the viewpoint of contractors and sub-contractors. Technological and Economic Development of Economy, 22(4), 631-618.

ICCPM. (2012). Complex Project Manager Competency Standards Version 4.1 (August 2012) Complex Project Management Leadership and Excellence. The International Centre for Complex Project Management.

Jami, A. A. N. and Walsh, P. R. (2014). The role of public participation in identifying stakeholder synergies in wind power project development: The case study of Ontario, Canada. Renewable Energy, 68, 194-202.

Jamshidi, M. (2012). Special section on complexity in engineering from complex systems science to complex systems technology. IEEE SYSTEMS JOURNAL, 6(3), 367-367.

Jasinski, D., Meredith, J., and Kirwan, K. (2015). A comprehensive review of full cost accounting methods and their applicability to the automotive industry. Journal of Cleaner Production, 108, 1123-1139.

Jones, T. M. (1995). Instrumental stakeholder theory: A synthesis of ethics and economics. Academy of management review, 20(2), 404-437.

Julian, R. (2016). Is it for donors or locals? The relationship between stakeholder interests and demonstrating results in international development. International Journal of Managing Projects in Business, 9(3), 505-527.

Kloprogge, P. and Van Der Sluijs, J. P. (2006). The inclusion of stakeholder knowledge and perspectives in integrated assessment of climate change. Climatic Change, 75(3), 359-389.

Krippendorff, K. and Bauer, M. W. (2007). Content analysis. An introduction to its methodology, 58(2), 329-331.

Laplume, A. O., Sonpar, K., and Litz, R. A. (2008). Stakeholder Theory: Reviewing a Theory That Moves Us. Journal of management, 34(6), 1152-1189. Liang, X., Shen, G. Q., and Guo, L. (2015). Improving Management of Green Retrofits from a Stakeholder Perspective: A Case Study in China. International Journal of Environmental Research and Public Health, 12(11), 13823-13842.

Littau, P., Jujagiri, N. J., and Adlbrecht, G. (2010). 25 Years of Stakeholder Theory in Project Management Literature (1984-2009). Project Management Journal, 41(4), 17-29.

Live Vaagaasar, A. (2011). Development of relationships and relationship competencies in complex projects. International Journal of Managing Projects in Business, 4(2), 294-307.

Luyet, V., Schlaepfer, R., Parlange, M. B., and Buttler, A. (2012). A framework to implement Stakeholder participation in environmental projects. Journal of Environmental Management, 111, 213-219.

Margineanu, D. G. (2013). Systems biology, complexity, and the impact on antiepileptic drug discovery. Epilepsy and Behavior, 38, 131-142.

Martinez, N. M. (2016). Towards a network place branding through multiple stakeholders and based on cultural identities The case of "The Coffee Cultural Landscape" in Colombia. Journal of Place Management and Development, 9(1), 73-90.

McKenna, A. and Metcalfe, M. (2013). The linguistic turn in project conceptualization. International Journal of Project Management, 31(8), 1154-1162.

Mitchell, R. K., Agle, B. R., and Wood, D. J. (1997). Toward a Theory of Stakeholder Identification and Salience: Defining the Principle of Who and What Really Counts. The Academy of Management Review, 22(4), 853-886.

Mok, K. Y., Shen, G. Q., and Yang, J. (2015). Stakeholder management studies in mega construction projects: A review and future directions. International Journal of Project Management, 33(2), 446-457.

Moodley, K., Smith, N., and Preece, C. N. (2008). Stakeholder matrix for ethical relationships in the construction industry. Construction Management and Economics, 26(6), 625-632.

Morsing, M. and Schultz, M. (2006). Corporate social responsibility communication: stakeholder 
information, response and involvement strategies. Business Ethics: A European Review, 15(4), 323-338.

Mozaffari, M. M., Fazli, S., and Sedaghat-Seresht, A. (2012). Identifying the most critical project complexity factors using Delphi method: the Iranian construction industry. Management Science Letters, 2(8), 2945-2952.

Mushove, P. and Vogel, C. (2005). Heads or tails? Stakeholder analysis as a tool for conservation area management. Global Environmental Change, 15(3), 184-198.

Nogueira, S. and Pinho, J. C. (2015). Stakeholder Network Integrated Analysis: The Specific Case of Rural Tourism in the Portuguese Peneda-Geres National Park. International Journal of Tourism Research, 17(4), 325-336.

O’Toole, K., Keneley, M., and Coffey, B. (2013). The participatory logic of coastal management under the project state: Insights from the Estuary Entrance Management Support System (EEMSS) in Victoria, Australia. Environmental Science \& Policy, 27, 206214.

Olander, S. and Landin, A. (2005). Evaluation of stakeholder influence in the implementation of construction projects. International Journal of Project Management, 23(4), 321-328.

Ommen, N. O., Blut, M., Backhaus, C., and Woisetschlager, D. M. (2016). Toward a better understanding of stakeholder participation in the service innovation process: More than one path to success. Journal of Business Research, 69(7), 24092416.

Pacagnella Júnior, A. C., Porto, G. S., Pacífico, O., and Salgado Júnior, A. P. (2015). Project stakeholder management: A case study of a Brazilian science park. Journal of Technology Management and Innovation, 10(2), 39-49.

Pickering, C. M. and Byrne, J. A. (2013). The benefits of publishing systematic quantitative literature reviews for $\mathrm{PhD}$ candidates and other early-career researchers.

PMI. (2008). A guide to the project management body of knowledge (PMBOK guide) (Vol. 4th;Fourth;). Newtown Square, Pa: Project Management Institute, Inc.

Podestá, G. P., Natenzon, C. E., Hidalgo, C., and Ruiz Toranzo, F. (2013). Interdisciplinary production of knowledge with participation of stakeholders: A case study of a collaborative project on climate variability, human decisions and agricultural ecosystems in the Argentine Pampas. Environmental Science \& Policy, 26, 40-48.

Pryke, S., Pryke, S., and Smyth, H. (2006). Projects as networks of relationships. The management of complex projects: A relationship approach, 213-235.

Rizzo, E., Pesce, M., Pizzol, L., Alexandrescu, F. M., Giubilato, E., Critto, A., . . . and Bartke, S. (2015). Brownfield regeneration in Europe: Identifying stakeholder perceptions, concerns, attitudes and information needs. Land Use Policy, 48, 437-453.

Rowley, T. J. (1997). Moving beyond Dyadic Ties: A Network Theory of Stakeholder Influences. The Academy of Management Review, 22(4), 887-910.

Sæbø, Ø., Flak, L. S., and Sein, M. K. (2011). Understanding the dynamics in e-Participation initiatives: Looking through the genre and stakeholder lenses. Government Information Quarterly, 28(3), 416-425.
Savage, G. T., Nix, T. W., Whitehead, C. J., and Blair, J. D. (1991). Strategies for Assessing and Managing Organizational Stakeholders. The Executive, 5(2), 6175.

Selin, C. and Hudson, R. (2010). Envisioning nanotechnology: New media and future-oriented stakeholder dialogue. Technology in Society, 32(3), 173-182.

Sharma, A., Sengupta, S., and Gupta, A. (2011). Exploring risk dimensions in the Indian software industry. Project Management Journal, 42(5), 78-91.

Sherrington, D. (2010). Physics and complexity. Philosophical Transactions: Mathematical, Physical and Engineering Sciences, 368(1914), 1175-1189.

Sitas, N., Reyers, B., Cundill, G., Prozesky, H. E., Nel, J. L., and Esler, K. J. (2016). Fostering collaboration for knowledge and action in disaster management in South Africa. Current Opinion in Environmental Sustainability, 19, 94-102.

Soste, L., Wang, Q. J., Robertson, D., Chaffe, R., Handley, S., and Wei, Y. P. (2015). Engendering stakeholder ownership in scenario planning. Technological Forecasting and Social Change, 91, 250-263.

Strand, R. and Freeman, R. E. (2015). Scandinavian cooperative advantage: The theory and practice of stakeholder engagement in Scandinavia. Journal of Business Ethics, 127(1), 65-85.

Thomas, S. (2014). Blue carbon: Knowledge gaps, critical issues, and novel approaches. Ecological Economics, 107, 22-38.

Toal, S. A., King, J. A., Johnson, K., and Lawrenz, F. (2009). The unique character of involvement in multisite evaluation settings. Evaluation and Program Planning, 32(2), 91-98.

Turner, J. R. (2009). The handbook of project-based management: leading strategic change in organizations: McGraw-hill.

Turner, R. and Zolin, R. (2012). Forecasting Success on Large Projects: Developing Reliable Scales to Predict Multiple Perspectives by Multiple Stakeholders Over Multiple Time Frames. Project Management Journal, 43(5), 87-99.

van Offenbeek, M. A. G., and Vos, J. F. J. (2016). An integrative framework for managing project issues across stakeholder groups. International Journal of Project Management, 34(1), 44-57.

Vidal, L.-A., Marle, F., and Bocquet, J.-C. (2011). Measuring project complexity using the Analytic Hierarchy Process. International Journal of Project Management, 29(6), 718-727.

Walker, D. H. T., Bourne, L. M., and Shelley, A. (2008). Influence, stakeholder mapping and visualization. Construction Management and Economics, 26(6), 645-658.

Walton, R. (2013). Stakeholder Flux: Participation in Technology-Based International Development Projects. Journal of Business and Technical Communication, 27(4), 409-435.

Wasserman, S., Galaskiewicz, J., and Publications, S. (1994). Advances in social network analysis: research in the social and behavioral sciences. Thousand Oaks, Calif: Sage Publications.

Weber, R. P. (1990). Basic content analysis, Newbury Park, Sage Publications.

Whitesides, G. M., and Ismagilov, R. F. (1999). Complexity in Chemistry. Science, 284(5411), 89-92. 
Williams, N. L., Ferdinand, N., and Pasian, B. (2015). Online Stakeholder Interactions in the Early Stage of a Megaproject. Project Management Journal, 46(6), 92110.

Wilson, E. J., Bunn, M. D., and Savage, G. T. (2010). Anatomy of a social partnership: A stakeholder perspective. Industrial Marketing Management, 39(1), 76-90.

Windapo, A. and Qamata, G. (2015). Evaluation of the Satisfaction Metrics used by Stakeholders on Large Engineering Projects. Journal of Engineering, 5(2), 82-90.

Yang, J., Shen, G. Q., Ho, M., Drew, D. S., and Xue, X. (2011). Stakeholder management in construction: An empirical study to address research gaps in previous studies. International Journal of Project Management, 29(7), 900-910.

Yang, R. J. (2014). An investigation of stakeholder analysis in urban development projects: Empirical or rationalistic perspectives. International Journal of Project Management, 32(5), 838-849.

Yang, R. J. and Zou, P. X. W. (2014). Stakeholderassociated risks and their interactions in complex green building projects: A social network model. Building and Environment, 73, 208-222.

Yang, R. J., Zou, P. X. W., and Wang, J. (2016). Modelling stakeholder-associated risk networks in green building projects. International Journal of Project Management, 34(1), 66-81.

Zhou, J. and Wang, H. Z. (2015). An Empirical Study on Stakeholder Management of Post-disaster Reconstruction Based on Interpretation System. Journal of Industrial Engineering and ManagementJiem, 8(5), 1409-1427.

Zidane, Y. J. T., Johansen, A., Ekambaram, A., and Hald, L. C. (2015). When Stakeholders Shape Successes or Bring Failures - A Case Study of an Algerian Megaproject. Procedia Computer Science, 64, 844851.

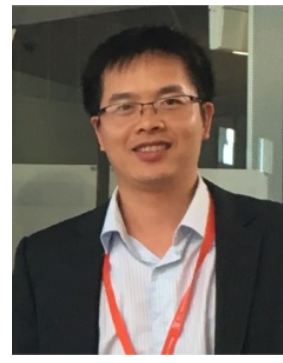

Mr. Tuan Son Nguyen received his BSc in Electrical and Electronics Engineering in Vietnam in 2008, and MEng in Engineering Management from Griffith University, Australia in 2014. He is currently a HDR candidate at the School of Engineering and Built Environment and a member of the Cities Research Institute at Griffith University. His research interests are in project management. He focuses on the development of theoretical knowledge and operational tools needed for effective management of supply chain and stakeholder management in the context of decision making, process improvement, and project feasibility.

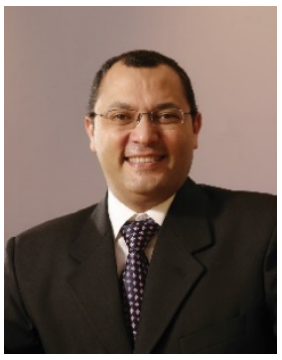

Professor Sherif Mohamed is Head of School of Engineering and Built Environment at Griffith University, Australia. He is actively engaged in scholarly research focusing on the development of theoretical knowledge and operational tools needed for effective implementation and evaluation of process improvement initiatives. He has supervised more than 20 successful $\mathrm{PhD}$ completions addressing a variety of topics related to project management and construction safety.

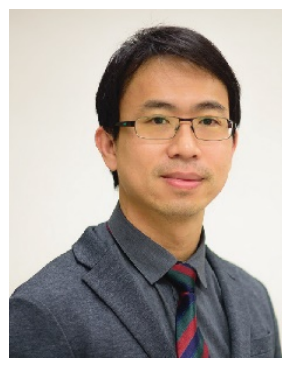

Dr. Kriengsak Panuwatwanich is currently an Assistant Professor at the School of Civil Engineering and Technology, Sirindhorn International Institute of Technology (SIIT) in Thailand. Prior to joining SIIT, he was a Senior Lecturer and Program Director at the School of Engineering, Griffith University in Australia. He currently serves as the President of the Association of Engineering, Project, and Production Management (EPPM). He also served as the 2014 Chairman of Engineers Australia Gold Coast Regional Group.

Appendix A. Research rule

\begin{tabular}{ll}
\hline Databases & Research rule \\
\hline Web of & Topic (stakeholder) and Topic (complex \\
Science & project) \\
& Refined by: Document Type (Article) \\
& Timespan: 1997-2016 \\
Timopus & Title-Abs-key (stakeholder) and Title- \\
& Abs-key (complex project) and Doc \\
& Type (ar) and Pub-Year > 1996 and \\
& (Limit-To (Subj-area, "Busi”) or Limit to \\
& (Subj-area, "Engi”)) and (Limit to \\
& (Exact-Key-Word, "Stakeholder”)) \\
\hline
\end{tabular}

Appendix B. Research themes

Research Authors

themes

SA (Hjortso et al., 2005); (Mushove and Vogel, 2005); (Kloprogge and Van Der Sluijs, 2006); (Walker et al., 2008); (Aaltonen et al., 2008); (Ballejos and Montagna, 2008); (Moodley et al., 2008); (Aaltonen and Kujala, 2010); (Wilson et al., 2010); (Aaltonen, 2011); (Sæbø et al., 2011); (Live Vaagaasar, 2011); (Beringer et al., 2012); (Blokhuis et al., 2012); (Elias, 2012); (Bal et al., 2013); (Bowden et al., 2013); (De Brucker et al., 2013); (Podestá et al., 2013); (Ariza et al., 2014); (Caniato et al., 2014); (De Schepper et al., 2014); (Yang and Zou, 2014); (Yang, 2014); (Aaltonen et al., 2015); (Liang et al., 2015); (Nogueira and Pinho, 2015); (Pacagnella Júnior et al., 2015); (Rizzo et al., 2015); (Williams et al., 2015); (Zhou and Wang, 2015); (Afreen and Kumar, 2016); (Debrie and Raimbault, 2016); (Herazo and Lizarralde, 2016); (Julian, 2016); (van Offenbeek and Vos, 2016); (Yang et al., 2016).

SI (Aaltonen et al., 2008); (Aaltonen and Kujala, 2010); (Aaltonen et al., 2015).

SMS (Walker et al., 2008); (Aaltonen and Sivonen, 2009); (Aaltonen and Kujala, 


\begin{tabular}{ll}
\hline $\begin{array}{l}\text { Research } \\
\text { themes }\end{array}$ & Authors \\
& 2010); (Aaltonen, 2011); (De Schepper et \\
al., 2014); (Aaltonen et al., 2015); \\
(Pacagnella Júnior et al., 2015). \\
(Hjortso et al., 2005); (Mushove and \\
SE & Vogel, 2005); (Kloprogge and Van Der \\
& Sluijs, 2006); (Walker et al., 2008); \\
& (Henriksen and Barlebo, 2008); (Chung et \\
& al., 2009); (Toal et al., 2009); (Davis et al., \\
& 2010); (Selin and Hudson, 2010); (Wilson \\
& et al., 2010); (Sæbø et al., 2011); (Beringer \\
& et al., 2012); (Blokhuis et al., 2012); \\
& (Burgin et al., 2013); (Bal et al., 2013); \\
& (Bowden et al., 2013); (De Brucker et al., \\
& 2013); (O’Toole et al., 2013); (Podestá et \\
& al., 2013); (Walton, 2013); (Jami and \\
& Walsh, 2014); (Gramberger et al., 2015); \\
& (Cascetta et al., 2015); (Fulton et al., \\
& 2015); (Havard et al., 2015); (Rizzo et al., \\
& 2015); (Soste et al., 2015); (Herazo and \\
& Lizarralde, 2016); (Martinez, 2016); \\
(Ommen et al., 2016); (Sitas et al., 2016).
\end{tabular}

Appendix C. SI Strategies (Aaltonen et al., 2008).

\begin{tabular}{|c|c|}
\hline SI Strategies & Description \\
\hline Direct & a stakeholder restricts a project's \\
\hline withholding & access to stakeholders' critical \\
\hline strategy & resources \\
\hline Indirect & a stakeholder influences a project's \\
\hline withholding & access to resources that are not directly \\
\hline strategy & controlled by the specific stakeholder \\
\hline Coalition & a stakeholder builds an ally with other \\
\hline $\begin{array}{l}\text { building } \\
\text { strategy }\end{array}$ & project stakeholders \\
\hline Resource & a stakeholder acquires and recruits \\
\hline building & critical and capable resources to their \\
\hline $\begin{array}{l}\text { strategy } \\
\text { Conflict }\end{array}$ & group \\
\hline $\begin{array}{l}\text { Conflict } \\
\text { escalation }\end{array}$ & $\begin{array}{l}\text { a stakeholder attempts to escalate the } \\
\text { conflict beyond the initial project- }\end{array}$ \\
\hline strategy & related causes \\
\hline Creditability & a stakeholder increases their perceived \\
\hline building & legitimacy by acquiring credible and \\
\hline strategy & capable resources \\
\hline $\begin{array}{l}\text { Communicat } \\
\text { ion strategy }\end{array}$ & $\begin{array}{l}\text { a stakeholder uses various types of } \\
\text { media to communicate and increase the } \\
\text { perceived legitimacy and urgency of } \\
\text { their requirement }\end{array}$ \\
\hline $\begin{array}{l}\text { Direct action } \\
\text { strategy }\end{array}$ & $\begin{array}{l}\text { a stakeholder organizes protests or road } \\
\text { blockades }\end{array}$ \\
\hline
\end{tabular}

Appendix D. Supplementary data

http://www.ppml.url.tw/EPPM_Journal/volumns/08_02_J

uly_2018/Appendix_D.pdf 